\title{
Biological Markers of Pathological Aging in Diseases of Men \\ ${ }^{1,2}$ Kiryl I. Prashchayeu, ${ }^{1}$ Nina I. Zhernakova, ${ }^{2,3}$ Alexandr A. Pranovich, ${ }^{2}$ AndreyN.IInitskiy, ${ }^{1}$ Andrey A. Grishenko \\ 1 "Belgorod National Research University", Russia (308015, Belgorod, Pobeda Street, 85), \\ ${ }^{2}$ Autonomous non-commercial organization "Research medical center "Gerontology", Moscow, Russia (125319, Moscow, 1-ya Aeroportovskaya Str., d 6, flat VI, room 1-4) \\ ${ }^{3}$ Autonomous non-profit scientific organization of higher education research center "Saint-Petersburg Institute of Bioregulation and gerontology", (197110 Russia, Saint-Petersburg, Dynamo pr., 3)
}

*Email: zhernakova@bsu.edu.ru

\section{Received: 21st October 2017 Accepted: 16th November 2017, Published: 31st December 2017}

\begin{abstract}
This article searches for biological urogenital tract markers on the urothelium hyperfunction model in systemic atherosclerosis. We revealed the main parameters of pathological aging of urogenital tract. We have obtained the data that the pathological aging of urogenital tract is characterized by a significant increase in the acetylcholine expression from 0.52 to $0.82 \mathrm{cu}$, glutamate - from 0.53 to 0.83 $\mathrm{cu}$, beta-1 transforming growth factor - from 0.452 to $0.497 \mathrm{ng} / \mathrm{ml}$ and a decrease in the levels of optical expression area in serotonin urothelium from 0.43 to $0.36 \mathrm{cu}$ and dopamine - from 0.42 to $0.35 \mathrm{cu}$. Within the framework of this article, we have proved that the indicators of urothelium expression of acetylcholine, glutamate, beta-1 transforming growth factor (an increase of their expression indicates pathological aging), the urothelium expression rates of serotonin and dopamine (a decrease in their expression indicates pathological aging) can be used as the biological markers of the pathological aging of urogenital tract on the combination model of urothelium hyperfunction and systemic atherosclerosis.
\end{abstract}

Keywords: Biological Markers, Urogenital Tract, Hyperactive Bladder, Pathological Aging, Acetylcholine, Glutamate, Beta-1 Transforming Growth Factor, Serotonin, Dopamine.

\section{Introduction}

In recent years, in connection with the development of a preventive trend in preventive gerontology, an increased attention is being paid to the search for pathological aging biological markers. And the development of preventive programs for men is of increasing interest $[1,2]$.

Such condition as a hyperactive bladder is the most significant gerontological problems in the incidence of men (GAB) [3]. The emergence of GAB is a big problem for men and leads to a decrease in social and physical activity with a decrease in productivity or a total refusal to work, forced restriction of sexual contacts, loss of self-esteem. The risk of developing a hyperactive bladder syndrome increases with age. The age of over 60 years old, where the GAB prevalence is maximal, is critical. An increase in the GAB risk for men is due not only to the age muscle disjunction, but also to the prostate hyperplasia, the signs of which are more or less present in about $50 \%$ of men aged 60 years old $[4,5,6]$.

The role of concomitant diseases with a neurogenic and vascular component, such as diabetes mellitus, cerebrovascular pathology, atherosclerosis of large vessels, and others, which can cause or exacerbate detrusor contractility disorders, is undoubted for the GAB development in elderly patients. A special place is occupied by systemic atherosclerosis, diagnosed in $50-70 \%$ of cases of elderly people with GAB [7, 8, 9]. According to many sources, both $G A B$ itself and $G A B$ in combination with systemic atherosclerosis is pathology typical for men over 60 years old and is not an age norm and a characteristic of normal aging. That is why the presence of these conditions indicates the urogenital tract pathological aging [10, 11, 12].

Thus, in connection with the above, a high practical significance is the search for the pathological aging biological markers, as well as the opportunity to generalize and systematize the biological markers of urogenital tract pathological aging.

\section{Objective}

To reveal the biological markers of urogenital tract pathological aging on the model of urothelium hyperfunction in systemic atherosclerosis.

\section{Materials and Methods}

The study included 278 people. 93 men of middle age, 92 men of elderly age and 93 men of senile age. The patients were divided into the following groups:

a) three groups of men aged 53.6 \pm 2.7 years old (middle age from 45 to 59 years old, $\mathrm{n}=31$ ), $67.8 \pm 2.3$ years old (elderly age from 60 to 74 years old, $\mathrm{n}=30$ ), $84.2 \pm 1.9$ years old (senile age from 75 to 89 years old, $\mathrm{n}=32$ ) - without signs of hyperactive bladder and systemic atherosclerosis;

b) three groups of men aged $54.7 \pm 2.3$ years old (middle age from 45 to 59 years old, $\mathrm{n}=30$ ), 
$66.4 \pm 2.5$ years old (elderly age from 60 to 74 years old, $\overline{\mathrm{n}}=31$ ), $85.7 \pm 1.1$ years old (senile age from 75 to 89 years old, $\mathrm{n}=30$ ) - with the signs of hyperactive bladder and systemic atherosclerosis;

c) three groups of men aged $55.9 \pm 2.6$ years old (middle age from 45 to 59 years old, $\mathrm{n}=32$ ), $68.2 \pm 2.2$ years old (elderly age from 60 to 74 years old, $\bar{n}=31$ ), $86.3 \pm 1.6$ years old (senile age from 75 to 89 years old, $n=31$ ) - with a combination of hyperactive bladder and systemic atherosclerosis.

The GAB diagnosis was made in accordance with the recommendations of the Terminology Standardization Committee of the International Continence Society (ICS). The leading pathology in these patients from the cardiovascular system was systemic atherosclerosis, which was diagnosed in accordance with the WHO recommendations [13].

The immunocytochemical study is a method of microscopic study of cells, which provides a specific detection of signal molecule expression in them. The immunohistochemical study was performed according to a standard procedure. The samples of urothelium biopsy specimens were placed on coated slides (Sigma) with poly-L-lysine. The primary and secondary antibodies - monoclonal mouse anti-human antibodies - to various signaling molecules were used for the immunocytochemical studies. Visualization of the immunohistochemical reaction was carried out using a complex of avidin with biotinylated peroxidase (ABC-kit), followed by the horseradish peroxidase appearance with diaminobenzidine (Novocastra).

Statistical processing of the study materials was carried out on the personal computer IBM PC (Intel Pentium-III), Windows Millenuim with software and Statistica for Windows Version 6.0 (StatSoft Inc., USA) package.

\section{Results and Discussion}

Immunohistochemical study of the expression level of urothelium receptors to signaling molecules in men of different ages

We studied the expression level of the following signaling urothelium molecules in men of different ages in the course of thesis research: beta-1 transforming growth factor (expression level in the lysate), acetylcholine, glutamate, serotonin, dopamine (levels of optical expression area).

The data for studying the biological features of expression of beta-1 transforming growth factor in the biopsy urothelium specimens in men of different ages are presented in Table 1.

Table 1: Biological Features of Expression of Beta-1 Transforming Growth Factor in Urothelium Cells in Men of Different Ages

\begin{tabular}{|l|l|l|l|}
\hline \multirow{2}{*}{ Nosological characteristics } & \multicolumn{2}{l|}{$\begin{array}{l}\text { The expression level of beta-1 transforming growth factor in the } \\
\text { lysate of urothelium cells in patients of different ages (ng/ml) }\end{array}$} \\
\cline { 2 - 4 } & $\begin{array}{l}\text { Middle age } \\
(\mathrm{n}=93)\end{array}$ & $\begin{array}{l}\text { Elderly age } \\
(\mathrm{n}=92)\end{array}$ & $\begin{array}{l}\text { Senile age } \\
(\mathrm{n}=93)\end{array}$ \\
\hline $\begin{array}{l}\text { Without GAB and systemic } \\
\text { atherosclerosis }\end{array}$ & $0.435 \pm 0.07$ & $0.434 \pm 0.06$ & $0.435 \pm 0.05$ \\
\hline $\begin{array}{l}\text { With GAB and systemic } \\
\text { atherosclerosis }\end{array}$ & $0.435 \pm 0.05$ & $0.441 \pm 0.07^{*, 0}$ & $0.453 \pm 0.08^{* *, \#}$ \\
\hline $\begin{array}{l}\text { The combination of GAB and } \\
\text { systemic atherosclerosis }\end{array}$ & $0.452 \pm 0.09^{\circ, 00}$ & $0.478 \pm 0.08^{*, 0,00}$ & $0.452 \pm 0.09^{\circ, 00}$ \\
\hline
\end{tabular}

$* \mathrm{p}<0.05$, difference in indicators between the groups of elderly and middle-aged patients;

$* * p<0.05$, difference in indicators between the groups of senile and elderly patients; $\# \mathrm{p}<0.05$, difference in indicators between the groups of senile and middle-aged patients; ${ }^{\circ} \mathrm{p}<0.05$, difference in indicators between the groups of patients with GAB and without pathology;

${ }^{\circ 0} \mathrm{p}<0.05$, difference in indicators between the groups of patients with $\mathrm{GAB}+$ atherosclerosis and with GAB.

The age-related biological features of expression of beta-1 transforming growth factor in the biopsy specimens of urothelium cells consisted in the fact that healthy people had no changes in the expression of beta- 1 transforming growth factor $(p>$ 0.05 ) with increasing age. A significant increase in the expression of beta-1 transforming growth factor was observed with increasing age $(p<0.05)$ and with increasing pathology severity $(\mathrm{p}<0.05)$ with
GAB without systemic atherosclerosis and $G A B$ with systemic atherosclerosis.

Data on the biological features of the optical area of acetylcholine expression in urothelium cells in men of different ages are presented in Table 2 .

The obtained data testified that the age-related biological features of the optical area of acetylcholine expression in urothelial cells are subject to the same regularities as the expression of beta-1 transforming growth factor. 
Table 2: Biological Features of the Optical Area of Acetylcholine Expression in Urothelium Cells in Men of Different Ages

\begin{tabular}{|l|l|l|l|}
\hline \multirow{2}{*}{ Nosological characteristics } & \multicolumn{2}{l}{$\begin{array}{l}\text { The optical area of acetylcholine expression in patients of different } \\
\text { ages }(\mathrm{cu})\end{array}$} \\
\cline { 2 - 4 } & $\begin{array}{l}\text { Middle age } \\
(\mathrm{n}=93)\end{array}$ & $\begin{array}{l}\text { Elderly age } \\
(\mathrm{n}=92)\end{array}$ & $\begin{array}{l}\text { Senile age } \\
(\mathrm{n}=93)\end{array}$ \\
\hline Without GAB and systemic atherosclerosis & $0.31 \pm 0.05$ & $0.32 \pm 0.06$ & $0.33 \pm 0.03$ \\
\hline With GAB and systemic atherosclerosis & $0.45 \pm 0.08^{\circ}$ & $0.52 \pm 0.07^{*, 0}$ & $0.64 \pm 0.06^{* *, \#, 0}$ \\
\hline $\begin{array}{l}\text { The combination of GAB and systemic } \\
\text { atherosclerosis }\end{array}$ & $0.52 \pm 0.07^{\circ, 00}$ & $0.67 \pm 0.04^{*, 0,00}$ & $0.82 \pm 0.08^{* *, \#, 0,00}$ \\
\hline
\end{tabular}

$* \mathrm{p}<0.05$, difference in indicators between the groups of elderly and middle-aged patients;

$* * p<0.05$, difference in indicators between the groups of senile and elderly patients;

$\# \mathrm{p}<0.05$, difference in indicators between the groups of senile and middle-aged patients;

${ }^{\circ} \mathrm{p}<0.05$, difference in indicators between the groups of patients with GAB and without pathology;

${ }^{\circ 0} \mathrm{p}<0.05$, difference in indicators between the groups of patients with $\mathrm{GAB}+$ atherosclerosis and with GAB.

The biological features of the optical area of glutamate expression in urothelium cells in men of different ages obeyed the same regularities (Table $3)$.

Table 3: Biological Features of the Optical Area of Glutamate Expression in Urothelium Cells in Men of Different Ages

\begin{tabular}{|l|l|l|l|}
\hline \multirow{2}{*}{ Nosological characteristics } & \multicolumn{2}{|l|}{$\begin{array}{l}\text { The optical area of glutamate expression in patients of different ages } \\
(\mathrm{cu})\end{array}$} \\
\cline { 2 - 4 } & $\begin{array}{l}\text { Middle age } \\
(\mathrm{n}=93)\end{array}$ & $\begin{array}{l}\text { Elderly age } \\
(\mathrm{n}=92)\end{array}$ & $\begin{array}{l}\text { Senile age } \\
(\mathrm{n}=93)\end{array}$ \\
\hline Without GAB and systemic atherosclerosis & $0.32 \pm 0.04$ & $0.33 \pm 0.06$ & $0.34 \pm 0.08$ \\
\hline With GAB and systemic atherosclerosis & $0.47 \pm 0.09^{\circ}$ & $0.57 \pm 0.08^{*, 0}$ & $0.69 \pm 0.09^{* *, \#, 0,00}$ \\
\hline $\begin{array}{l}\text { The combination of GAB and systemic } \\
\text { atherosclerosis }\end{array}$ & $0.53 \pm 0.06^{0,00}$ & $0.69 \pm 0.05^{*, 0,00}$ & $0.83 \pm 0.07^{* *, \#, 0,00}$ \\
\hline
\end{tabular}

$* \mathrm{p}<0.05$, difference in indicators between the groups of elderly and middle-aged patients;

$* * \mathrm{p}<0.05$, difference in indicators between the groups of senile and elderly patients;

$\# \mathrm{p}<0.05$, difference in indicators between the groups of senile and middle-aged patients;

${ }^{\circ} \mathrm{p}<0.05$, difference in indicators between the groups of patients with GAB and without pathology;

${ }^{\text {oo }} \mathrm{p}<0.05$, difference in indicators between the groups of patients with $\mathrm{GAB}+$ atherosclerosis and with GAB.

The next stage of our study was the study of optical area of serotonin expression in urothelium cells in men of different ages (Table 4). The age-related biological features of serotonin expression consisted in the fact that healthy people had no significant changes in the optical area of serotonin expression in urothelium cells with increasing age ( $p>0.05)$. It was observed a decrease in serotonin expression with GAB without systemic atherosclerosis in comparison with people without pathology $(p<0.05)$, however no age differences were revealed $(p>0.05)$. But it was observed a significant decrease in expression with increasing age ( $\mathrm{p}<0.05)$ and with increasing pathology severity $(p<0.05)$ with the combination of $G A B$ and systemic atherosclerosis.

Table 4: Biological Features of the Optical Area of Serotonin Expression in Urothelium Cells in Men of Different Ages

\begin{tabular}{|l|l|l|l|}
\hline \multirow{2}{*}{ Nosological characteristics } & \multicolumn{2}{|l|}{ The optical area of serotonin expression $(\mathrm{cu})$} \\
\cline { 2 - 4 } & $\begin{array}{l}\text { Middle age } \\
(\mathrm{n}=93)\end{array}$ & $\begin{array}{l}\text { Elderly age } \\
(\mathrm{n}=92)\end{array}$ & $\begin{array}{l}\text { Senile age } \\
(\mathrm{n}=93)\end{array}$ \\
\hline $\begin{array}{l}\text { Without GAB and systemic } \\
\text { atherosclerosis }\end{array}$ & $0.56 \pm 0.07$ & $0.55 \pm 0.04$ & $0.54 \pm 0.05$ \\
\hline With GAB and systemic atherosclerosis & $0.50 \pm 0.04^{\circ}$ & $0.46 \pm 0.04^{\circ}$ & $0.44 \pm 0.07^{\circ}$ \\
\hline $\begin{array}{l}\text { The combination of GAB and systemic } \\
\text { atherosclerosis }\end{array}$ & $0.43 \underline{ \pm 0.050},^{\text {oo }}$ & $0.40 \pm 0.04^{\circ, 00}$ & $0.36 \pm 0.06^{* *, \#, 0,00}$ \\
\hline
\end{tabular}

$* \mathrm{p}<0.05$, difference in indicators between the groups of elderly and middle-aged patients;

$* * \mathrm{p}<0.05$, difference in indicators between the groups of senile and elderly patients;

$\# p<0.05$, difference in indicators between the groups of senile and middle-aged patients; 
${ }^{\circ} \mathrm{p}<0.05$, difference in indicators between the groups of patients with GAB and without pathology;

${ }^{\circ 0} \mathrm{p}<0.05$, difference in indicators between the groups of patients with $\mathrm{GAB}+$ atherosclerosis and with $\mathrm{GAB}$.

Similar regularities have been revealed with respect to the biological features of optical area of dopamine expression in urothelium cells in men of different ages (Table 5).

Table 5: Biological Features of the Optical Area of Dopamine Expression in Urothelium Cells in Men of Different Ages

\begin{tabular}{|l|l|l|l|}
\hline \multirow{2}{*}{ Nosological urothelium characteristics } & \multicolumn{3}{|l|}{ The optical area of dopamine expression (cu) } \\
\cline { 2 - 4 } & $\begin{array}{l}\text { Middle age } \\
(\mathrm{n}=93)\end{array}$ & $\begin{array}{l}\text { Elderly age } \\
(\mathrm{n}=92)\end{array}$ & $\begin{array}{l}\text { Senile age } \\
(\mathrm{n}=93)\end{array}$ \\
\hline Without GAB and systemic atherosclerosis & $0.55 \pm 0.06$ & $0.54 \pm 0.03$ & $0.53 \pm 0.04$ \\
\hline With GAB and systemic atherosclerosis & $0.49 \pm 0.05^{\circ}$ & $0.45 \pm 0.06^{\circ}$ & $0.43 \pm 0.06^{\circ}$ \\
\hline $\begin{array}{l}\text { The combination of GAB and systemic } \\
\text { atherosclerosis }\end{array}$ & $0.42 \pm 0.04^{0,00}$ & $0.39 \pm 0.03^{0,00}$ & $0.35 \pm 0.05^{* *, \#, 0,00}$ \\
\hline
\end{tabular}

*p<0.05, difference in indicators between the groups of elderly and middle-aged patients;

$* * \mathrm{p}<0.05$, difference in indicators between the groups of senile and elderly patients;

$\# \mathrm{p}<0.05$, difference in indicators between the groups of senile and middle-aged patients;

${ }^{\circ} \mathrm{p}<0.05$, difference in indicators between the groups of patients with GAB and without pathology;

${ }^{\circ 0} \mathrm{p}<0.05$, difference in indicators between the groups of patients with $\mathrm{GAB}+$ atherosclerosis and with GAB.

Thus, we have found that the urogenital tract physiological aging is characterized by stable expression levels of such urothelium signaling molecules as acetylcholine, glutamate and beta- 1 transforming growth factor.

The urogenital tract pathological aging was characterized by a significant increase in the acetylcholine expression in uterine cells by 1.4 times, glutamate - by 1.6 times, beta- 1 transforming growth factor - by 1.5 times and a decrease in serotonin and dopamine levels - by 1.2 times.

This made it possible to conclude that the indices of increased expression of acetylcholine, glutamate, beta-1 transforming growth factor and decreased urothelium indices of serotonin and dopamine expression could be considered as biological markers of the urogenital tract pathological aging(Fig. 1).

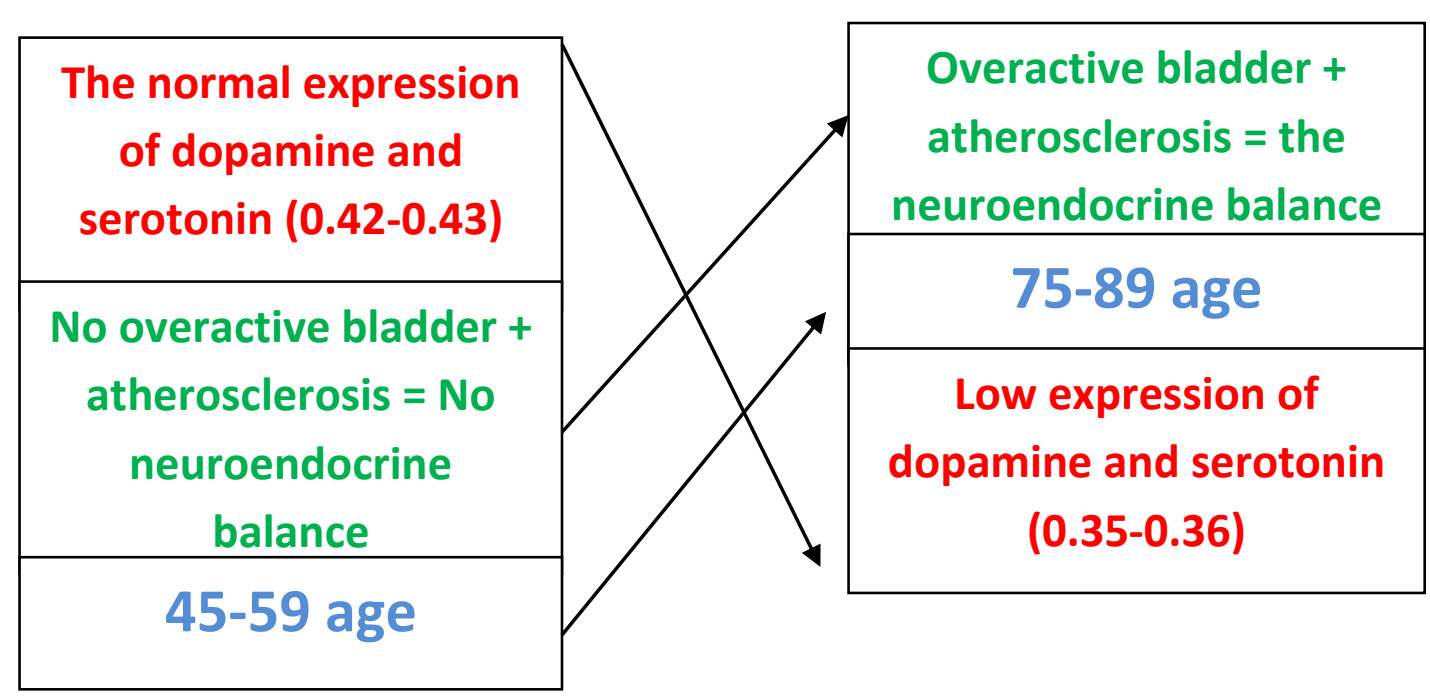

Fig. 1.Integral Risk of the Urogenital Tract Pathological Aging

\section{Summary}

1. The urogenital tract physiological aging is characterized by stable expression indices of beta-1 transforming growth factor in the lysate of uterine cells at an average level of $0.435 \mathrm{ng} / \mathrm{ml}$, as well as the absence of statistically significant fluctuations in the optical density of expression of acetylcholine, glutamate, serotonin and dopamine in urothelium. 2. The pathological aging of urogenital tract is characterized by a significant increase in the acetylcholine expression from 0.52 to $0.82 \mathrm{cu}$, glutamate - from 0.53 to $0.83 \mathrm{cu}$, beta- 1 
transforming growth factor - from 0.452 to 0.497 $\mathrm{ng} / \mathrm{ml}$ and a decrease in the levels of optical expression area in serotonin urothelium - from 0.43 to $0.36 \mathrm{cu}$ and dopamine - from 0.42 to $0.35 \mathrm{cu}$.

3. The indicators of urothelium expression of acetylcholine, glutamate, beta-1 transforming growth factor (an increase of their expression indicates pathological aging), the urothelium expression rates of serotonin and dopamine (a decrease in their expression indicates pathological aging) can be used as the biological markers of the pathological aging of urogenital tract on the combination model of urothelium hyperfunction and systemic atherosclerosis.

\section{References}

[1] Apolikhin, O.I., Sevryukov F.A., KalininskayaA.A., Prostate Hyperplasia: Medical and Social Aspects, Modern Technologies of Surgical Treatment, 2012. Academy of Natural History: 115-134.

[2] Lebedev, V.V. Violations of Male Reproductive Health and Ways of their Prevention, 2012. Abstract: 15-24.

[3] Kulchavenya, E.V., BrizhatyukE.V., BreusovA.A. Hyperactive Bladder as a Mask of Chronic Prostatitis, 2012. Urology, 6: 43-47.

[4] Lesovoy, V.N., KolupaevS.M. Cytokines in the Hyperactive Bladder Pathogenesis, 2013. Scientific Bulletin of the Belgorod State University, 18: 3739.

[5] Chernyshev, A.V. System and Quality of Medical Care for Patients with Male Reproductive Health Disorders and Possible Ways of Improvement, 2010. Bulletin of TSU, 2: 679-684.

[6] Chancellor, M.B.The overactive bladder progression to underactive bladder hypothesis, 2014. IntUrolNephrol, 46: 23-27.

[7] Schwarz, P.G., GoryachevF.K., PlotnikovA.N., SavvinD.Yu., Popov S.V. Differential Diagnosis and Treatment of Neurogenic and Psychogenic Urination Disorders Using the Example of Hyperactive Bladder Syndrome, 2013. Therapeutic Archive, 9: 86-92.

[8] Chuang, Y.C., Kaufmann J.H., Chancellor D.D., Chancellor M.B., KuoH.C.Bladder instillation of liposome encapsulated onabotulinumtoxinaimproves overactive bladder symptoms: a prospective, multicenter, double blind, randomized trial, 2014. Journal Urology, 192(6): 1743-1749.

[9] Yamamichi, F., Shigemura K., Behnsawy H.M., Yamashita M., Shirakawa T., Fujisawa M. Beta-3 adrenergic receptors could be significant factors for overactive bladder-related symptoms, 2015. Int Journal ClinExpPathol., 8: 11863-11870.

[10] Gormley, E.A., LightnerD.J., Faraday M., VasavadaS.P. Diagnosis and Treatment of Overactive Bladder (Non-Neurogenic) in Adults:
AUA/SUFU Guideline Amendment, 2015. The Journal of Urology, 193 (5): 1572-1580.

[11] Nambiar, A., Lucas M. Chapter 4: Guidelines for the diagnosis and treatment of overactive bladder (OAB) and neurogenic detrusor overactivity (NDO), 2014. NeurourolUrodyn, 33: 21-25.

[12] Veit-Rubin, N., Meyer S., Achtari C.Overactive bladder syndrome-a public health challenge, 2016. Rev Med Suisse, 11: 492-495.

[13] WHO, 42nd session of the World Health Organization - World Health Assembly, 42nd session "Prevention and Control of Cardiovascular and other Chronic Noncommunicable Diseases" and the International Statistical Classification of Diseases and Related Health Problems, 2014. 10th revision. 